Research Paper

\title{
Delayed Reduction of Hepatitis B Viral Load and Dynamics of Adefovir-Resistant Variants during Adefovir plus Entecavir Combination Rescue Therapy
}

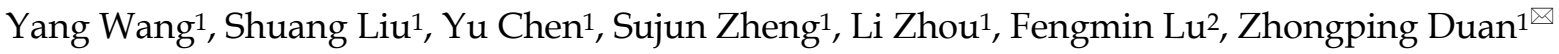 \\ 1. Artificial Liver Center, Beijing YouAn Hospital, Capital Medical University, Beijing 100069, China. \\ 2. Department of Microbiology \& Infectious Disease Center, Peking University Health Science Center, Beijing, China.
}

$\triangle$ Corresponding author: Professor Zhongping Duan, Artificial Liver Center, Beijing YouAn Hospital, Capital Medical University, 8 Xitoutiao, Youan Menwai Street, Beijing 100069, China. Tel: +86-10-63291007; Fax: +86-10-63295285; Email: duan2517@163.com

() 2015 Ivyspring International Publisher. Reproduction is permitted for personal, noncommercial use, provided that the article is in whole, unmodified, and properly cited. See http:/ /ivyspring.com/terms for terms and conditions.

Received: 2015.01.25; Accepted: 2015.04.20; Published: 2015.05.15

\begin{abstract}
Objective: Entecavir (ETV) added to adefovir (ADV) is recommended in the consensus for management of patients with ADV resistance. However, little attention has been focused on the delayed reduction of HBV DNA and dynamics of ADV-resistant variants during ADV-ETV combination rescue therapy in the clinical setting. We characterized the dynamics of viral load and resistant variants in nucleos $(\mathrm{t})$ ide analogues (NAs)-naïve chronic hepatitis $\mathrm{B}(\mathrm{CHB})$ patients during antiviral treatment with ADV monotherapy followed by ADV-ETV combination therapy.

Methods: A cohort of $55 \mathrm{CHB}$ patients was enrolled in this study. Three NAs-naive patients developed ADV-resistant variants during 24-33 months of ADV monotherapy, and then switched to ADV-ETV combination therapy. Thirty-five serial serum samples from these three patients were regularly collected during treatment. Ten mutants associated with commonly used antiviral drugs were detected by pyrosequencing.

Results: HBV DNA decreased to the lowest level during ADV monotherapy at 6-18 months, with a decrease of $0.95-5.51 \log _{10}$ copies $/ \mathrm{mL}$, whereas $\mathrm{rtA} 181 \mathrm{~V}$ or $\mathrm{rtN236T}$ gradually increased with extended therapy. HBV DNA decreased to below the detectable level during ADV-ETV combination therapy at $21-24$ months, with a decrease of $4.19-4.65 \log _{10}$ copies $/ \mathrm{mL}$. Resistant rtA181V and $\mathrm{rtN236T}$ were undetectable after 21-24 months of combination therapy. Moreover, no LAM-resistant rtM204I/V or ETV-resistant variants were detected during the 27-36 months of combination therapy.

Conclusion: Although ADV-resistant variants were suppressed, viral load reduction was delayed during ADV-ETV combination rescue therapy in patients with ADV-resistant HBV. The quantification of resistant variants by pyrosequencing may facilitate monitoring of antiviral therapy.
\end{abstract}

Key words: adefovir, entecavir, hepatitis B virus, rescue therapy, resistance

\section{Introduction}

Approximately 240 million individuals are chronically infected with hepatitis B virus (HBV) worldwide [1], and persistent active replication of HBV DNA is associated with progression of fibrosis, development of hepatocellular carcinoma, and liver-related mortality [2]. The treatment of chronic hepatitis $\mathrm{B}(\mathrm{CHB})$ has evolved with the inception of nucleos(t)ide analogues (NAs), including lamivudine
(LAM), adefovir dipivoxil (ADV), entecavir (ETV), telbivudine (LdT), and tenofovir (TDF), which all target HBV reverse transcriptase (RT) activity and inhibit viral replication [3]. These antiviral effects can improve the virological, biochemical and histological status in the majority of CHB patients. Unfortunately, during long-term NAs monotherapy, the selective pressure imposed by the NAs gradually favors an 
increase in virus harboring resistant variants in the RT domain, resulting in reduced susceptibility and resistance to NAs. Virological and biochemical breakthrough may emerge in the clinical setting, followed by liver disease progression [3-5].

ADV-resistant variants have posed a major challenge in the management of patients with $\mathrm{CHB}$, mainly due to the possibility of decreased efficacy for other NAs and undetermined optimal rescue therapy [6-8]. The antiviral potency of ADV in subjects receiving the approved daily dose of $10 \mathrm{mg}$ was well documented in two pivotal phase III clinical trials [9, 10]. However, long-term ADV monotherapy may lead to drug resistance characterized by an increase in viral load in an adherent patient. The cumulative incidence of ADV resistance was reported to be $0 \%$ at 1 year of treatment, $1-3 \%$ at year 2, 5-6\% at year 3 and $15-29 \%$ at year 5 [11-13]. The principal resistant variants associated with ADV resistance are located in domain B and $\mathrm{D}$ of the HBV polymerase. They include $\mathrm{rtA} 181 \mathrm{~V} / \mathrm{T}$ and $\mathrm{rtN236T}$ [14]. This has resulted in a focus on rescue therapy. Although ADV-resistant variants have more or less reduced susceptibility to other NAs in vitro [15], several rescue regimens have been used in patients with ADV-resistant variants based on the current knowledge of cross-resistance, and most of these patients benefit from these rescue therapies. Therefore, add-on LAM, LdT, ETV, and switching to TDF were all included in the up-to-date clinical practice guidelines for the management of patients with ADV resistance [16-19]. However, due to limited available clinical data, to date, the optimal treatment option for patients with ADV resistance has not been available.

Understanding the dynamics of resistant variants under different antiviral pressure may contribute to better treatment strategies and thus prevent undesirable clinical outcomes. LAM add-on in most patients with ADV-resistant variants can suppress the replication of wild-type and ADV-resistant HBV. However, previous longitudinal studies [5, 20-22] showed that, in some patients, the replication of ADV-resistant variants may not be fully inhibited by ADV-LAM combination rescue therapy. This may be attributed to an ADV-resistant variant, rtA181V/T, which is responsible for cross-resistance to LAM and ADV. Moreover, as TDF is not available in some regions of Asia, ADV plus ETV is considered a promising option after previous ADV treatment failure in a large number of $\mathrm{CHB}$ patients. Based on the current knowledge of cross drug resistance, it is reasonable to predict that non-cross-resistant NAs could be used as rescue regimens in the management of $\mathrm{CHB}$ patients with resistant variants. However, to our knowledge, little attention has been focused on the delayed re- duction of viral load and the dynamics of ADV-resistant variants during ADV-ETV combination rescue therapy in the clinical setting.

In this serial study, the dynamics of viral load were documented in detail, and pyrosequencing was conducted to characterize the dynamics of ADV-resistant variants during antiviral therapy with ADV monotherapy followed by ADV-ETV combination rescue therapy.

\section{Materials and Methods}

\section{Patients}

Fifty five CHB patients were consecutively enrolled in present study from June 2007 to July 2008 in Beijing YouAn Hospital, Capital Medical University, China. Of this cohort, 29 were NAs-naïve patients and the other 26 were LAM-treated patients. These patients were treated with $10 \mathrm{mg}$ of ADV once daily. None of these patients required dose reduction due to inadequate renal function. Following the development of ADV resistance, ETV $0.5 \mathrm{mg}$ daily was added to the ongoing ADV treatment as salvage therapy. During the 60 months of observation, only 3 of 29 NAs-naïve patients developed ADV resistance, therefore their antiviral regimen was switched to ADV-ETV combination therapy. CHB was diagnosed according to the AASLD guideline [23]. None of the patients was co-infected with hepatitis delta virus, hepatitis $C$ virus, or human immunodeficiency virus.

The patients were followed from when they started ADV monotherapy. They were consecutively monitored every three months in the first year of therapy, and every six months thereafter throughout the treatment course. During each follow-up, serum specimens were collected for liver function tests, viral marker tests and HBV DNA quantification. Any remaining serum samples were stored at $-80^{\circ} \mathrm{C}$ for subsequent research. There were no reported issues concerning medication noncompliance.

The study was conducted in compliance with the Declaration of Helsinki. Use of the research samples was approved by the Medical Ethics Review Committee of Beijing YouAn Hospital. All patients provided written informed consent authorizing us to access their medical records and to store the remaining serum specimens for research purposes.

\section{Measurement of liver function and HBV DNA quantification}

Alanine aminotransferase (ALT) and aspartate aminotransferase (AST) were measured using an Olympus Automatic Biochemical Analyzer AU5400 (Olympus, Tokyo, Japan) with a cut-off value of 40 $\mathrm{IU} / \mathrm{L}$. The viral markers, including serum HBsAg, 
$\mathrm{HBeAg}$ and anti-HBe, were determined using an electrochemiluminescence immunoassay (Abbott Laboratories, Chicago, IL, USA). The serum HBV DNA level was determined using the Cobas HBV Amplicor Monitor assay (Roche Diagnostics, Pleasanton, CA, USA), with a lower limit of detection of $2.46 \log _{10}$ copies/mL $(\sim 50 \mathrm{IU} / \mathrm{mL}$ or 291 copies/mL).

\section{Detection of antiviral-resistant mutations}

The pyrosequencing assay was performed according to the standard protocol for the HBV Drug Resistance Mutation Detection Test kit (Qiagen, Shenzhen, China) and the PyroMark Q24 MDx system (Qiagen GmbH, Hilden, Germany). HBV DNA purification reagents, gene amplification primers and sequencing primers were included in this kit and obtained from Qiagen Biotech Co. Ltd. (Shenzhen, China). The procedure was performed as previously described [24]. We analyzed 10 mutation sites (rtL169, rtV173, rtL180, rtA181, rtT184, rtA194, rtS202, rtM204, rtN236, and rtM250) on the RT domain of HBV DNA polymerase which were previously reported to be associated with HBV drug resistance [25].

\section{Results}

\section{Characteristics of the patients at initiation of ADV monotherapy}

The three patients were aged between 22 and 45 years. The emergence of ADV-resistant variants, such as rtA181V and/or rtN236T, was found in all these patients during the 24 - 33 months of ADV monotherapy. Their antiviral regimen was switched to ADV plus ETV combination therapy as salvage therapy and none of the patients required dose reduction due to insufficient renal or liver function. Two patients received percutaneous liver biopsy examination at initiation of ADV monotherapy and at 60 months of therapy. Their clinical characteristics at initiation of ADV monotherapy and ADV-ETV combination therapy are shown in Table 1.

\section{Clinical course of ADV monotherapy followed by ADV-ETV combination rescue therapy}

The duration of ADV monotherapy was 24 to 33 months. The mean duration of ADV monotherapy was 11 months (range 6-18) which resulted in a decrease in viral load to the lowest level during ADV monotherapy, with an average change of $-3.96 \log _{10}$ copies/mL (range -0.95 to -5.51 ). The patients then switched to ADV-ETV combination therapy, and the duration of combination therapy was 27 to 36 months. The mean duration of ADV-ETV combination therapy was 22.67 (range 21-24) months which resulted in a decrease in viral load, with an average change of
$-4.42 \log _{10}$ copies/mL (range -4.19 to -4.65 ). The clinical course of these three patients by antiviral therapy is illustrated in Fig. 1.

During 60 months of treatment, none of the patients achieved loss of HBeAg or HBsAg, or seroconversion to $\mathrm{HBe} A b$ or hepatitis $B$ surface antibody. After 60 months of treatment, the inflammation and fibrosis scores on liver biopsy showed a 1-3 and 0-1 point decrease, respectively, according to the Ishak scoring system.

Table 1. Clinical features of the chronic hepatitis B patients treated with ADV monotherapy followed by ADV-ETV combination therapy

\begin{tabular}{|c|c|c|c|}
\hline & Patient 1 & Patient 2 & Patient 3 \\
\hline \multicolumn{4}{|l|}{ Baseline } \\
\hline Gender & Male & Male & Male \\
\hline Age (yr) & 45 & 22 & 35 \\
\hline HBeAg & - & + & + \\
\hline HBV genotype & B & $\mathrm{C}$ & $\mathrm{C}$ \\
\hline $\begin{array}{l}\text { Viral load } \\
\left(\log _{10} \text { copies } / \mathrm{mL}\right)\end{array}$ & 5.22 & 9.67 & 8.72 \\
\hline $\operatorname{ALT}(\mathrm{U} / \mathrm{L}) \dagger$ & 51.8 & 140.6 & 81.7 \\
\hline AST (U/L)† & 26.3 & 46.8 & 64.6 \\
\hline $\begin{array}{l}\text { Liver histology (inflamma- } \\
\text { tion/fibrosis) } \ddagger\end{array}$ & $8 / 3$ & - & $13 / 5$ \\
\hline \multicolumn{4}{|l|}{ During ADV mono-therapy } \\
\hline Duration of $\mathrm{ADV}(\mathrm{mo})$ & 31 & 33 & 24 \\
\hline ADV-resistant variants & N236T & A181V & $\mathrm{A} 181 \mathrm{~V}+\mathrm{N} 236 \mathrm{~T}$ \\
\hline \multicolumn{4}{|c|}{ During ADV-ETV combination therapy } \\
\hline $\begin{array}{l}\text { Viral load at the start } \\
\left(\log _{10} \text { copies } / \mathrm{mL}\right)\end{array}$ & 6.73 & 5.03 & 7.11 \\
\hline Duration of ADV-ETV (mo) & 29 & 27 & 36 \\
\hline $\begin{array}{l}\text { Liver histology at month } 60 \\
\text { (inflammation/fibrosis) } \ddagger\end{array}$ & $5 / 2$ & - & $12 / 5$ \\
\hline $\begin{array}{l}\text { † The upper limit of normal value } \\
\text { † Diagnosed according to Ishak } \\
\text { Abbreviations: ADV Adefovir: }\end{array}$ & $\begin{array}{l}40 \mathrm{U} / \mathrm{L} ; \mathrm{A} \\
\text { system. } \\
\text { tecavir: } \mathrm{AL}\end{array}$ & U/L. & \\
\hline
\end{tabular}

\section{Dynamics of ADV-resistant variants during ADV monotherapy followed by ADV-ETV combination rescue therapy}

Three resistant viral populations were found during ADV administration in these three patients, including rtN236T alone (patient 1), rtA181V alone (patient 2), and both rtA181V and rtN236T (patient 3). However, the dynamics of the HBV viral population varied in each patient. After 21-24 months of combination treatment, ADV-resistant variants rtA181V and rtN236T gradually decreased to undetectable levels. During 27-36 months of combination treatment, no LAM-resistant variants (rtM204I/V with or without rtL180M) or ETV-resistant variants (rtT184, rtS202, or rtM250) were detected in the viral population.

The dynamics of the resistant variants in these three patients were assessed by pyrosequencing analyses during antiviral treatment and are illustrated in Fig. 2. None of the patients harbored the ADV-resistant variant in the baseline samples. The 
ADV-resistant variants replaced the wild-type viral population and were predominant during ADV monotherapy. The replication of ADV-resistant variants (rtA181V and/or rtN236T) was inhibited after ETV was added to the ongoing ADV monotherapy. In patient 1, the proportion of the virus harboring rtN236T gradually increased for 6 months before virological breakthrough (defined as an increase in the HBV DNA level of more than $1 \log _{10}$ copies/mL compared to the nadir HBV DNA level during therapy). The virus harboring rtN236T was predominant and was responsible for virological breakthrough. In patient 2, the virological breakthrough occurred at month 12, however, none of the ADV-resistant variants was detected at this time point. The virus harboring rtA181V emerged at month 36 and was predominant at month 42 , while the wild-type virus was profoundly inhibited. In patient 3, the dynamics was characterized by outgrowth of the virus with rtN236T within the background of the virus harboring rtA181V and was predominant. In contrast to patient 1 , the virus with the single rtN236T variant was responsible for virological breakthrough.

\section{Discussion}

Prolonged monotherapy with ADV is associated with the emergence of ADV-resistant variants, and ETV added to ongoing ADV as a rescue regimen is included in the guidelines for management of patients

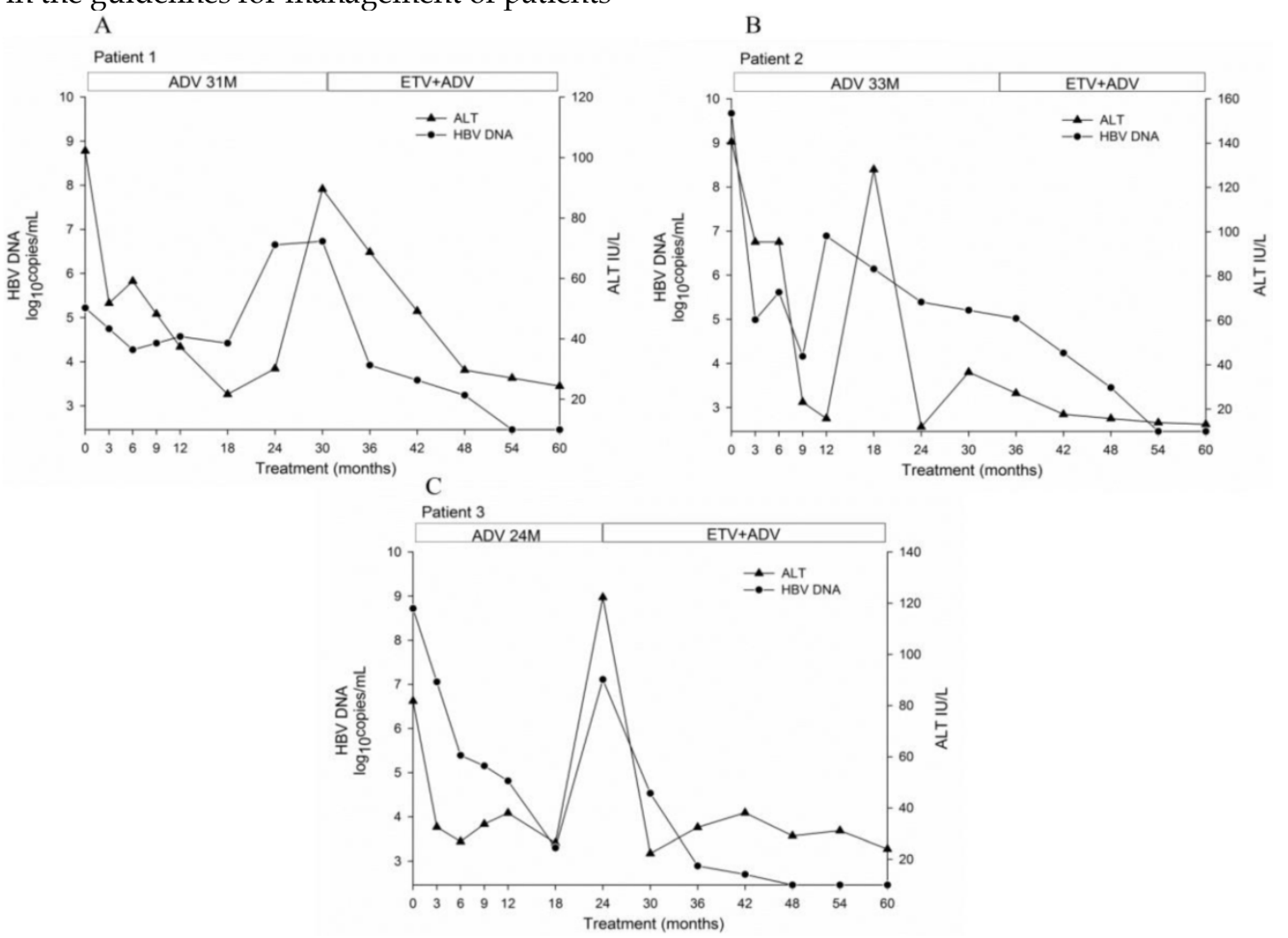

Figure 1. Clinical course during ADV monotherapy followed by ADV-ETV combination rescue therapy. The duration of therapy is indicated by the bars above the graph. A, patient 1; B, patient 2; C, patient3.

with ADV resistance $[17,18]$. However, little attention has been focused on the reduction time of HBV DNA and the dynamics of ADV-resistant variants during ADV-ETV combination rescue therapy. In this longitudinal study, in addition to the detailed clinical course, pyrosequencing was also carried out to characterize the dynamics of resistant variants during antiviral therapy with ADV monotherapy followed by ADV-ETV combination therapy. This study demonstrated that replication of the ADV-resistant variants, rtA181V and rtN236T, was fully inhibited by ADV-ETV combination rescue therapy. In addition, no LAM-resistant rtM204I/V or ETV-resistant variants were selected during 27-36 months of combination therapy. However, compared to most patients treated with ADV or ETV in a previous study [26, 27], serum HBV DNA decreased to an undetectable level after 24 weeks and the patients were much more likely to benefit from long-term antiviral therapy. In the present study, HBV DNA reduction was delayed, even with ADV-ETV combination therapy. Although the effect of delayed HBV DNA reduction on the benefit of rescue antiviral therapy was undetermined, our study indicates that NAs result in potent rapid suppression of viral replication and should be prescribed for NA-naïve patients in the clinical setting due to intractable sequential issues after the emergence of resistant variants.

http://www.medsci.org 

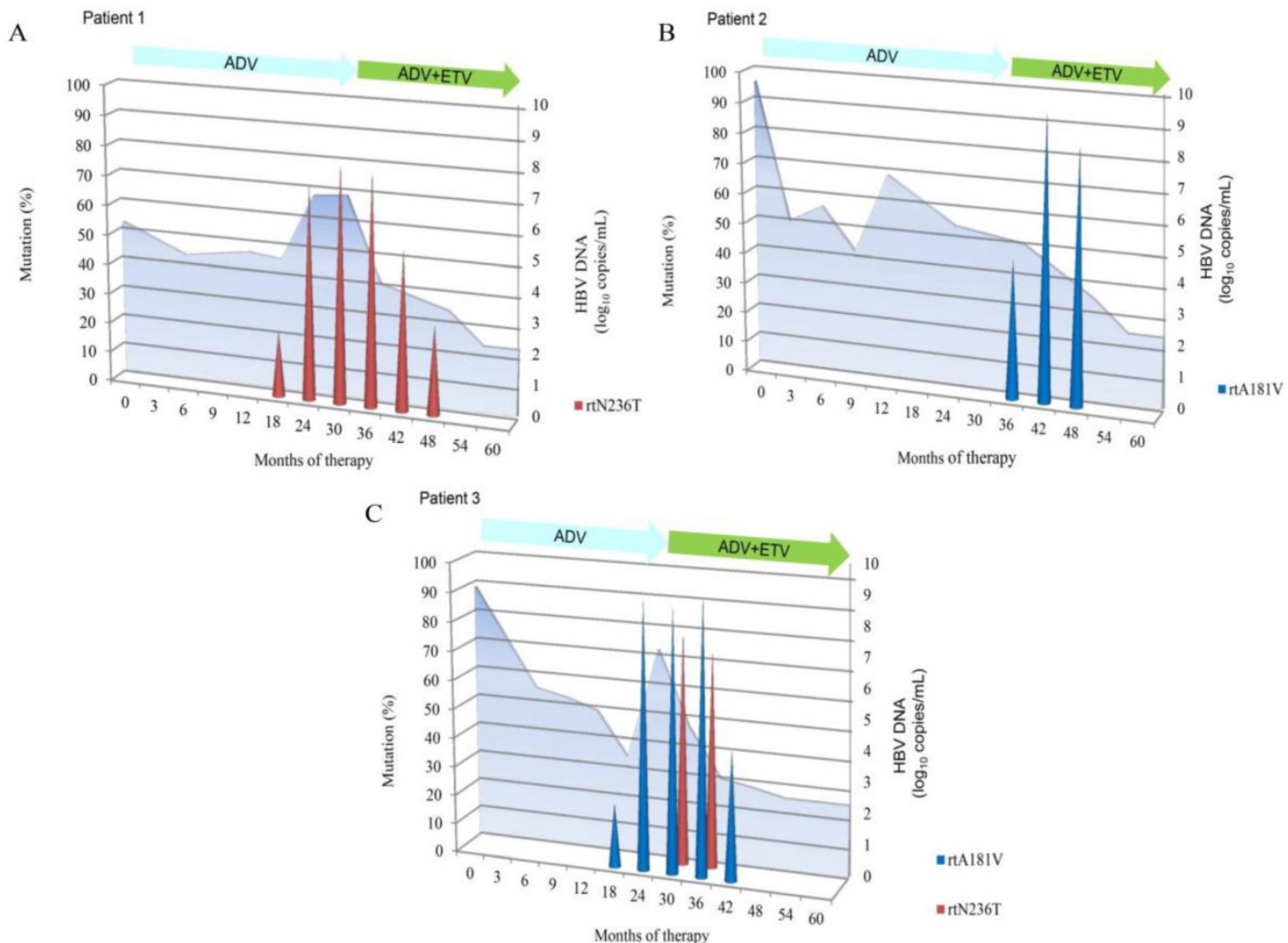

Figure 2. Dynamics of resistant variants during ADV monotherapy followed by ADV-ETV combination rescue therapy. Results are expressed as a proportion of each resistant variant at each time point in the viral population. HBV DNA levels are shown at the back in light blue. The duration of therapy is indicated by the bars above the graph. A, patient 1; B, patient 2; C, patient3.

Understanding the viral kinetics under different antiviral pressure may be useful in determining antiviral potency and optimizing therapeutic strategy. Lu et al. reported [28] that virological response at week 12 indicated a significant reduction in intrahepatic DNA at week 48. The role of the roadmap concept in patients receiving NAs with a high genetic barrier to resistance, such as TDF and ETV, has yet to be determined [27]. In this study, HBV DNA in these patients was still detectable after 12 months of ADV monotherapy. Due to the subsequent development of ADV resistance, this may indicate that either the addition or switch to another more potent NA without cross-resistance should be considered at this stage. Furthermore, virological breakthrough was considered the first manifestation of antiviral drug resistance during NAs treatment, however, not all virological breakthroughs were due to drug resistance [29-31]. In patients 1 and 3, the selection of ADV-resistant variants preceded virological breakthrough by six months, the resistant variants replaced the wild-type viral population and were predominant during monotherapy, which is consistent with a previous study $[5,20]$. Patient 2 had virological breakthrough without detected ADV-resistant variants at month 12. Possible reasons for this phenomenon include natural fluctuation of the HBV DNA concentration, differences in the absorption and metabolism of the drug [32], the sensitivity of the method used for assessing resistant variants, appearance of other mutations such as core and pre-core mutation that were not included in this study.

Data regarding the management of ADV resistance are limited. In one study [21], no significant difference in virological response between LAM-ADV and ETV rescue therapy was reported in patients with ADV-resistant variants, however, the incidence of ETV resistance was higher in patients treated with ETV monotherapy. Another recent study [16] showed that in ADV-resistant CHB patients, cumulative virological response rate was higher in patients treated with ETV-based therapy (ETV with or without ADV therapy) than in patients treated with LAM plus ADV combination therapy. This discrepancy may be due to the difference in rescue regimens in some patients. A previous study [33] reported that in six patients with resistance to or non-response to ADV, TDF-LAM suppressed the replication of HBV DNA to an undetectable level (400 copies $/ \mathrm{mL}$ ) at 12 months of treatment. One recent study demonstrated 
[34] that TDF plus ETV is a potent therapeutic option for patients with LAM and ADV resistance, the cumulative probability of virological suppression at month 6 was $75.0 \%$ in 28 patients. If TDF is not available, add-on LAM, LdT or ETV therapy is a practical treatment modality for patients with an ADV-resistant variant. However, the efficacy and safety profile of these regimens were not compared, therefore, to date, the optimal treatment option for patients with ADV-resistant variants has not yet been identified. Previous longitudinal studies demonstrated that, in some patients, ADV-LAM combination therapy may not fully inhibit the replication of ADV-resistant variants [5, 20, 22]. This is mainly attributed to the ADV mutation, $\operatorname{rtA} 181 \mathrm{~V} / \mathrm{T}$, which is responsible for cross-resistance to LAM and ADV. In rare cases, ADV-resistant variants may persist after switching to TDF monotherapy [35]. In contrast, in the present study, we observed that replication of the ADV-resistant variants, rtA181V and/or rtN236T, were fully inhibited after 21-24 months of ADV-ETV combination therapy. An undetectable level of resistant variants is a good response to rescue therapy. However, other studies have suggested that undetectable resistant variants may be a transition phase in the selective process of novel drug-resistant variants $[36,37]$.

It should be noted that during ADV-ETV combination rescue therapy, although the replication of ADV-resistant variants, rtA181V and/or rtN236T, was fully inhibited and no LAM-resistant rtM204I/V or ETV-resistant variants were selected after 27-36 months of combination rescue therapy, HBV DNA reduction was delayed even with potent ADV-ETV combination therapy. The delayed HBV DNA reduction related to the undesirable outcome of long-term rescue therapy is a concern and merits further investigation. Firstly, perhaps it is not surprising that suppression of ADV-resistant variants occurs with ADV-ETV combination therapy, as current knowledge indicates that there is no signature cross-resistant variant between ETV and ADV in vitro [29]. We first demonstrated this result in a clinical study, and partly corroborate the guideline recommendation for the management of patients with ADV resistance. Secondly, due to the delayed reduction of HBV DNA, in these rare cases, it is unknown whether a switch to a more potent antiviral regimen, such as TDF-ETV combination therapy, could eliminate a potential undesirable outcome that may emerge during extended rescue therapy. The applicability of the roadmap concept in patients receiving combination rescue therapy remains to be determined. However, HBV DNA quantification and the monitoring of resistant variants are still required during long-term rescue therapy. Thirdly, histological benefits may be negatively affected by the emergence of resistant variants during antiviral therapy [38]. In the present study, in addition to a good virological response, two patients had paired liver biopsies and both patients had an improvement in inflammation score and did not show progression of fibrosis. These results indicated that ADV-ETV combination rescue therapy may contribute to histological improvement. Whether ADV-resistant variants will re-emerge and LAM-resistant rtM204I/V or ETV-resistant variants (rtT184, rtS202, or rtM250) will be selected in these patients warrants further investigation.

Although a cohort of $55 \mathrm{CHB}$ patients was enrolled in this study and sensitive pyrosequencing was conducted to detect an average of 11 time-point serial samples for up to 60 months of treatment, our study has some limitations. These limitations include the small number of patients with ADV resistance and the relatively short duration of ADV-ETV combination therapy. Due to these limitations, further large cohort studies are needed to verify the antiviral potency and delayed HBV DNA reduction associated with this rescue regimen.

In conclusion, ADV-ETV combination rescue therapy fully inhibited the replication of ADV-resistant variants, and no LAM-resistant variants were detected during 27-36 months of ADV-ETV combination therapy. However, 21-24 months of ADV-ETV combination therapy contributed to a decrease in HBV DNA to below the detectable level. This may be attributed to ADV signature resistant variants (rtA181 or/and rtN236) having reduced susceptibility to ETV in vivo. Furthermore, in addition to the sensitivity of pyrosequencing, the additional benefit of resistant variant quantification may facilitate antiviral therapy monitoring.

\section{Acknowledgement}

Funding: This work was funded by the National Science and Technology Key Project (2012ZX10002004-006, 2012ZX10004904-003-001, 2013ZX10002002-006 and 2012ZX10002005); Ministry of Science and Technology of China (2012ZX09301002-006); The High Technical Personnel Training Item in Beijing Health System (2011-3-083, 2013-3-071); The Beijing Municipal Science \& Technology Commission (Z131107002213019); Beijing Municipal Administration of Hospitals Clinical medicine Development of special funding support (XM201308); National Key Subject Construction Project(WJWYA-2014-002).

\section{Competing Interests}

None declared. 


\section{References}

1. Ott JJ, Stevens GA, Groeger J, Wiersma ST. Global epidemiology of hepatitis B virus infection: new estimates of age-specific HBsAg seroprevalence and endemicity. Vaccine. 2012; 30: 2212-9.

2. Iloeje UH, Yang HI, Jen CL, Su J, Wang LY, You SL, et al. Risk and predictors of mortality associated with chronic hepatitis B infection. Clin Gastroenterol Hepatol. 2007; 5: 921-31.

3. Zoulim F, Locarnini S. Hepatitis B virus resistance to nucleos(t)ide analogues. Gastroenterology. 2009; 137: 1593-608.

4. Yuen MF, Sablon E, Hui CK, Yuan HJ, Decraemer H, Lai CL. Factors associated with hepatitis B virus DNA breakthrough in patients receiving prolonged lamivudine therapy. Hepatology. 2001; 34: 785-91.

5. Rodriguez C, Chevaliez S, Bensadoun P, Pawlotsky JM. Characterization of the dynamics of hepatitis B virus resistance to adefovir by ultra-deep pyrosequencing. Hepatology. 2013; 58: 890-901.

6. Patterson SJ, George J, Strasser SI, Lee AU, Sievert W, Nicoll AJ, et al. Tenofovir disoproxil fumarate rescue therapy following failure of both lamivudine and adefovir dipivoxil in chronic hepatitis B. Gut. 2011; 60: 247-54.

7. van Bommel F, de Man RA, Wedemeyer H, Deterding K, Petersen J, Buggisch $\mathrm{P}$, et al. Long-term efficacy of tenofovir monotherapy for hepatitis B virus-monoinfected patients after failure of nucleoside/nucleotide analogues. Hepatology. 2010; 51: 73-80.

8. Deterding K, Manns MP, Wedemeyer H. Does the presence of adefovir-resistant variants lead to failure of tenofovir monotherapy? Journal of hepatology. 2008; 49: 862-3.

9. Marcellin P, Chang TT, Lim SG, Tong MI, Sievert W, Shiffman ML, et al. Adefovir dipivoxil for the treatment of hepatitis B e antigen-positive chronic hepatitis B. N Engl J Med. 2003; 348: 808-16.

10. Hadziyannis SJ, Tassopoulos NC, Heathcote EJ, Chang TT, Kitis G, Rizzetto M, et al. Adefovir dipivoxil for the treatment of hepatitis B e antigen-negative chronic hepatitis B. N Engl J Med. 2003; 348: 800-7.

11. Hadziyannis SJ, Tassopoulos NC, Heathcote EJ, Chang TT, Kitis G, Rizzetto M, et al. Long-term therapy with adefovir dipivoxil for HBeAg-negative chronic hepatitis B. N Engl J Med. 2005; 352: 2673-81.

12. Hadziyannis SJ, Tassopoulos NC, Heathcote EJ, Chang TT, Kitis G, Rizzetto M, et al. Long-term therapy with adefovir dipivoxil for HBeAg-negative chronic hepatitis B for up to 5 years. Gastroenterology. 2006; 131: 1743-51.

13. Minde Z, Yimin M, Guangbi Y, JinLin H, Hao W, Hong R, et al. Five years of treatment with adefovir dipivoxil in Chinese patients with $\mathrm{HBeAg}$-positive chronic hepatitis B. Liver international : official journal of the International Association for the Study of the Liver. 2012; 32: 137-46.

14. Angus P, Vaughan R, Xiong S, Yang H, Delaney W, Gibbs C, et al. Resistance to adefovir dipivoxil therapy associated with the selection of a novel mutation in the HBV polymerase. Gastroenterology. 2003; 125: 292-7.

15. Villet S, Pichoud C, Billioud G, Barraud L, Durantel S, Trepo C, et al. Impact of hepatitis B virus rtA181V/T mutants on hepatitis B treatment failure. Journal of hepatology. 2008; 48: 747-55.

16. Kang SH, Yim HJ, Kim HR, Kang K, Suh SJ, Lee HJ, et al. Comparison of Lamivudine Plus Adefovir Therapy Versus Entecavir With or Without Adefovir Therapy for Adefovir-resistant Chronic Hepatitis B. J Clin Gastroenterol. 2014; 48: 889-95.

17. Liaw Y-F, Kao J-H, Piratvisuth T, Chan HLY, Chien R-N, Liu C-J, et al. Asian-Pacific consensus statement on the management of chronic hepatitis B: a 2012 update. Hepatol Int. 2012; 6: 531-61.

18. Lok AS, McMahon BJ. Chronic hepatitis B: update 2009. Hepatology. 2009; 50: 661-2.

19. European Association For The Study Of The L. EASL clinical practice guidelines: Management of chronic hepatitis B virus infection. J Hepatol. 2012; 57: 167-85.

20. Pallier C, Rodriguez C, Brillet R, Nordmann P, Hezode C, Pawlotsky JM. Complex dynamics of hepatitis $\mathrm{B}$ virus resistance to adefovir. Hepatology. 2009; 49: 50-9.

21. Chen $\mathrm{CH}$, Wang $\mathrm{JH}, \mathrm{Lu} \mathrm{SN}, \mathrm{Hu} \mathrm{TH}$, Hung $\mathrm{CH}$, Chang $\mathrm{MH}$, et al. Treatment response and evolution of $\mathrm{HBV}$ resistance during lamivudine plus adefovir or entecavir therapy in patients with adefovir-resistant mutants. Antivir Ther. 2012; 17: 701-9.

22. Ko SY, Kim BK, Kwon SY, Kim KH, Kim JH, Choe WH, et al. Clonal evolution of hepatitis B virus polymerase gene mutations during lamivudine-adefovir combination treatment. World journal of gastroenterology : WJG. 2012; 18: 6437-46; discussion $\mathrm{p} 45$.

23. Lok AS, McMahon BJ. Chronic hepatitis B. Hepatology. 2007; 45: 507-39.

24. Lee GH, Inoue M, Toh JK, Chong RH, Aung MO, Koay ES, et al. Two-step evolution of the hepatitis B drug-resistant mutations in a patient who developed primary entecavir resistance. Liver international : official journal of the International Association for the Study of the Liver. 2013; 33: 642-6.

25. Lok AS, Zoulim F, Locarnini S, Bartholomeusz A, Ghany MG, Pawlotsky JM, et al. Antiviral drug-resistant HBV: standardization of nomenclature and assays and recommendations for management. Hepatology. 2007; 46: 254-65.

26. Leung N, Peng CY, Hann HW, Sollano J, Lao-Tan J, Hsu CW, et al. Early hepatitis $B$ virus DNA reduction in hepatitis B e antigen-positive patients with chronic hepatitis B: A randomized international study of entecavir versus adefovir. Hepatology. 2009; 49: 72-9.
27. Gane EJ. The Roadmap concept: using early on-treatment virologic responses to optimize long-term outcomes for patients with chronic hepatitis B. Hepatology international. 2008; 2: 304-7.

28. Lu HY, Zhuang LW, Yu YY, Si CW. Virological response to antiviral therapy at week 12 indicates a great reduction of intrahepatic hepatitis B virus DNA and cccDNA in HBeAg-positive chronic hepatitis B patients. J Viral Hepat. 2010; 17 Suppl 1: 59-65.

29. Hongthanakorn C, Chotiyaputta W, Oberhelman K, Fontana RJ, Marrero JA, Licari $\mathrm{T}$, et al. Virological breakthrough and resistance in patients with chronic hepatitis $\mathrm{B}$ receiving nucleos(t)ide analogues in clinical practice. Hepatology. 2011; 53: 1854-63.

30. Carrouee-Durantel S, Durantel D, Werle-Lapostolle B, Pichoud C, Naesens L, Neyts J, et al. Suboptimal response to adefovir dipivoxil therapy for chronic hepatitis B in nucleoside-naive patients is not due to pre-existing drug-resistant mutants. Antivir Ther. 2008; 13: 381-8.

31. Hezode C, Chevaliez S, Bouvier-Alias M, Roudot-Thoraval F, Brillet R, Zafrani ES, et al. Efficacy and safety of adefovir dipivoxil $20 \mathrm{mg}$ daily in HBeAg-positive patients with lamivudine-resistant hepatitis B virus and a suboptimal virological response to adefovir dipivoxil $10 \mathrm{mg}$ daily. J Hepatol. 2007; 46: 791-6.

32. Chang UI, Lee YC, Wie SH, Jang JW, Bae SH, Choi JY, et al. Evolution of viral load and changes of polymerase and precore/core promoter sequences in lamivudine-resistant hepatitis B virus during adefovir therapy. Journal of medical virology. 2007; 79: 902-10.

33. Choe WH, Kwon SY, Kim BK, Ko SY, Yeon JE, Byun KS, et al. Tenofovir plus lamivudine as rescue therapy for adefovir-resistant chronic hepatitis $B$ in hepatitis B e antigen-positive patients with liver cirrhosis. Liver Int. 2008; 28: 814-20.

34. Lee YB, Lee JH, Lee DH, Cho H, Ahn H, Choi WM, et al. Efficacy of entecavir-tenofovir combination therapy for chronic hepatitis B patients with multidrug-resistant strains. Antimicrob Agents Chemother. 2014; 58: 6710-6.

35. van Bommel F, Trojan J, Deterding K, Wedemeyer H, Wasmuth HE, Huppe D, et al. Evolution of adefovir-resistant HBV polymerase gene variants after switching to tenofovir disoproxil fumarate monotherapy. Antivir Ther. 2012; 17: 1049-58

36. Villeneuve JP, Durantel D, Durantel S, Westland C, Xiong S, Brosgart CL, et al. Selection of a hepatitis $B$ virus strain resistant to adefovir in a liver transplantation patient. J Hepatol. 2003; 39: 1085-9.

37. Deng XL, Li QL, Guo JJ. Dynamics of lamivudine-resistant hepatitis B virus strains in patients with entecavir rescue therapy. Virus genes. 2013; 47: 1-9.

38. Dienstag JL, Goldin RD, Heathcote EJ, Hann HW, Woessner M, Stephenson $\mathrm{SL}$, et al. Histological outcome during long-term lamivudine therapy. Gastroenterology. 2003; 124: 105-17. 